\title{
Is Spanish Becoming more Gender Fair? A Historical Perspective on the Interpretation of Gender-specific and Gender-neutral Expressions*
}

\author{
Uwe Kjær Nissen (Odense)
}

\begin{abstract}
During the last three decades, many recommendations for a gender fair Spanish language have been proposed, but, generally speaking, it has been the substitution of the so-called 'masculine generic' (e.g. los profesores 'the teachers [masc.]') by gender neutral (e.g. el profesorado 'the staff of teachers) or explicit references (e.g. los profesores $y$ (las) profesoras 'the teachers [masc. and fem., resp.]') which has been favoured. Two important assumptions are implicit in these recommendations. First, the sentences containing the masculine forms would lead to associations primarily to men (thus leaving women 'invisible'), whereas sentences containing either the gender-neutral forms or the gender-explicit references would evoke a generic association. Second, the associations between form and mental representation are considered inalterable and unlikely to change over time.
\end{abstract}

This paper intends to interrogate these assumptions by means of two questionnaire investigations that were carried out in Spain in 1995 and 2005 in which native speakers of Spanish were asked to complete specific filler sentences.

The results of both investigations demonstrate that there is no clear-cut correspondence between certain linguistic forms and the mental (gender-) representations evoked in peoples' minds. For example, a masculine form is not automatically connected with a male image. The investigation also shows that some associations significantly change over time; for example, a clear male bias of the masculine form in the first study seems to have vanished within a time span of ten years. With respect to another aim of the gender fair recommendations - namely to make women more visible in public discourse - the investigations show that this, indeed, is best achieved by explicitly referring to women. Interestingly, this result appears to be stable over time.

Altogether, it seems justifiable to conclude that the assumptions underlying the recommendations for a gender fair language can be challenged. At any rate, it is important to point out that these assumptions are subject to change over time - at least within politically influenced language matters - and perhaps faster than has been expected.

\section{Introduction}

In keeping with the growing feminist movement in Spain in the middle 1980s concerns were raised, like in many other countries, as to the interpretation of generic words and expressions and, consequently, the first guidelines for non-sexist language were published (Ministerio ...

\footnotetext{
* I would like to express my gratitude to my colleagues, José Luis Aliaga (University of Zaragoza), Marina Fernández Lagunilla (Universidad Autónoma, Madrid) and Francisco J. Ruiz de Mendoza (University of Logroño) for distributing the questionnaires to their students. My thanks also to Annelise Christensen, who typed in all of the data and checked the first names that could not readily be classified as either female or male with native speakers. I am also very grateful to Professor Werner Vach for his invaluable support with respect to the statistical analysis of the data. I am grateful to all the students who responded to the questionnaires in this study. Finally, I want to thank the anonymous referees for many valuable comments that have strengthened the arguments considerably.
} 
1988; UNESCO 1990). In principle, these guidelines were in line with similar guidelines published previously in other languages, e.g. French, English and German (Miller/Swift 1981; Guentherodt et al. 1980; Dumai 1988), whose recommendations undoubtedly have been used as the basis for formulating similar guidelines for Spanish. ${ }^{1}$ As a matter of fact, today an enormous variety of guidelines exist; also many districts and autonomous regions in Spain have published their own recommendations (e.g. Ayuntamiento de Valladolid 1996; Errazu Colás 1995; Asociación Cultural Simone de Beauvoir 2006; Instituto de la Mujer, Gobierno de Canarias 2010) and some even in their own, regional language, e.g. Valencian (Departamento de la Dona 1987). ${ }^{2}$ Internet courses for the avoidance of sexist language are currently available (Diputación de Córdoba 2005) and even private institutions, such as banks, have devised their own recommendations (Caja de ahorros El MONTE 2005). Recently guidelines have also appeared in Latin America (e.g. Ramírez Vélez 2009). It is even possible today to get texts in Spanish analyzed online in order to eradicate sexist expressions (see Tincluye.org 2008). All the above-mentioned guidelines generally recommend avoiding the 'masculine generic' (i.e. the masculine gender used as a generic reference for both women and men) by substituting it with other presumed gender fair forms ${ }^{3}$, e.g. gender neutral forms like profesorado ('staff of teachers') or dual forms like e.g. los profesores y (las) profesoras ('the teachers', masc. and fem., respectively). These proposals rest basically on the assumption that the masculine form - due to a close connection between grammatical gender and the sex of the referent - would lead people to think of men and, consequently, leave women invisible.

Empirical investigations have been carried out for English and German and, more recently, also for French ${ }^{4}$ where, in general, it has been proven that the English pronoun he and certain German and French masculine words with reference to human beings function as very poor candidates for a generic interpretation (cf. Brauer/Landry 2008; Gastil 1990; Gygax et al. 2008; Gygax/Gabriel 2008; Hamilton 1988; Irmen/Roßberg 2004; MacKay 1980; Martyna 1978; Moulton et al. 1978; Ng 1994; Rothermund 1998; Stahlberg/Sczesny/Braun 2001). However, investigations that intend to establish correlations between supposed generic forms and their actual interpretations are still rare for Spanish. To my knowledge, there are currently only two such studies, Nissen (1997) and Núñez Cedeño (1999), the former dealing with the interpretation of noun forms, the latter with the interpretation of the Spanish pronoun él ('he'). ${ }^{5}$ On the whole, only a minimal amount of concern has been voiced as to whether or not

\footnotetext{
1 Surprisingly, there are no references in the Spanish guidelines to those for Canadian French which were produced at the same time (e.g. Dumais 1988 and 1992) although both languages have very similar structures. Even recently edited Spanish guidelines make no reference to their Canadian equivalents. In contrast, the Spanish guidelines refer to similar guidelines edited in France, but, interestingly, according to Fleischmann (1997), "The Canadian Office de la Langue Française" was at that time (and probably still is) more sensitive to actual usage than the "Commissariat de la Langue Française" and the "Academie Française" in France.

${ }^{2}$ For further references see e.g. Krugova (2007). This author describes more than 35 official language manuals, plans of action, policy decisions, and laws at the national, regional, and local level. See also Bengoechea (2000) who gives a thorough account of guidelines to avoid sexist language edited by government institutions and agencies and the negative responses from the press and academia.

3 As the term "gender" has linguistic as well as social/psychological meaning, researchers often avoid using "gender" and prefer to use "sex" in descriptions that also deal with grammatical gender (e.g. Henley/Abueg 2003 , footnote 2). In this paper I will use "gender" for the social/psychological category, and "grammatical gender" for the linguistic one.

${ }^{4}$ With respect to the Italian language a considerable amount of literature exists (see e.g. Marcato/Thüne 2002 and Luraghi/Olita 2006), but to the best of my knowledge, there have been no specific studies on the interpretation of the masculine generic. However, the activation of gender stereotypes for Italian role nouns has been tested (Cacciari/Padovani 2007).

5 Two other questionnaire-based investigations merit a mention as they, too, focus on the interpretation of certain expressions (Calero 2006, 2007). However, both employ a more sociolinguistic approach: The first one examines how Spanish grammatical gender and certain professional denominations are perceived by informants
} 
the forms recommended by the guidelines for Spanish, published in 1988, actually function as intended. The present article intends to remedy the lack of empirical research in relation to Spanish by providing an analysis of language use over time, which will shed light on whether changes have taken place over time in the interpretation of the forms in question, whether the intentions of the recommendations are still reflected in more recent language use and whether such recommendations still seem appropriate. To my knowledge, no research has been carried out for Spanish adopting such a historical perspective ${ }^{6}$ with comparable data.

\section{Terminological clarifications}

Before explaining the design and the results of the study, some terminological clarifications are needed, especially because two ways of talking about "gender neutrality" are addressed. On the one hand, "gender-neutral language" deals with linguistic forms that do not overtly show specific gender markers. This term is explained in section 2.1. On the other hand, 'gender neutral' can also be understood in terms of cognition, addressing the question of how people interpret certain linguistic forms, i.e. which "psycholinguistic reality" lies behind the form used (cf. the title of Klein's investigation from 1988). This aspect will be dealt with in section 2.2 .

\subsection{Masculine, gender neutral and dual forms}

Generally, the proposals for a non-sexist language operate with three different groups of words. The first group consists of masculine forms. These forms are defined traditionally on syntactic grounds: they show masculine concordance with their modifiers. Characteristically, with respect to references to human beings, a feminine counterpart exists for each masculine form (e.g. trabajador ('worker' [masc.]) vs. trabajadora ('worker' [fem.]). A few words do not allow the $-o /-a$ alternation and in these cases the distinction is made lexically (e.g. padre 'father' vs. madre 'mother'). The second group, which consists of gender neutral forms, can be divided into two groups: 1) the collectives (e.g. gente 'people' or población 'population'), and 2) singular words that lack a counterpart of the opposite grammatical gender (e.g. la persona 'person' [fem.] or el individuo 'individual' [masc.]; words like *el persono or *la individua do not exist in Spanish). Gender neutral words are the only words that may refer indiscriminately to women, men and both women and men: cf. María es buena persona, Pedro es buena persona, and María y Pedro son buenas personas (buena persona = 'nice person'). Thus, from the morphology or from the syntactic behaviour of gender neutral words alone, it is not possible to infer any reference to the person's gender. Bear in mind that this is not the case with the masculine words: cf. Maria y Pedro son buenos campesinos, Pedro es buen campesino, but not *María es buen campesino (buen campesino = 'good farmer'). ${ }^{7}$ In

of various age, sex and educational background; the second one deals with the perception of women and men's genderlects.

${ }^{6}$ Although the investigations mentioned in the introduction were undertaken during the last 30 years, a direct comparison of these over time is not possible as they are all based on diverging experimental methods. (See e.g. Henley/Abueg (2003) and Irmen/Linner (2005) for summaries and comparisons of earlier investigations). One exception is Rubin/Greene/Schneider (1994) that make comparisons over three decades. However the scope of their investigation differs considerably, as they focus solely on the use of gender-fair language in speeches given by male corporate executives. Also Nagle (2008) focuses on the development over time (i. e. women's attitudes across the entire lifespan), but her method is totally different from the one employed in this paper, as her informants are women (only) aged 20 to 88 .

7 In traditional Spanish grammar, gender neutral words, i. e. words that are "formally, linguistically unmarked for gender" (Frank/Treichler 1989: 18), are often referred to as 'epicene' words (see Real Academia Española 1977: 175f.). According to this tradition, both single gender nouns such as personas (f) 'persons' and generically used masculine nouns such as abuelos (m) 'grandparents', 'grandfathers' belong to the category of epicene words on the grounds that both forms may refer to women and men. However, this use of the term "epicene" must not be confused with "gender neutral". As a matter of fact, masculine words cannot refer to women alone and thus, 
general, masculine nouns used generically cannot refer to women alone; simply, because a corresponding noun of the feminine gender is available. The third group of words consists of the dual forms ${ }^{8}$. This term refers to making explicit reference to both women and men by means of (a) duplication, (b) splitting or (c) amalgamation. Thus, the dual forms of e.g. los alumnos ('the students' [masc.]) are (a) los alumnos y (las) alumnas ${ }^{9}$, (b) los/las alumnos/as or (c) l@salumn@s ('the students' [masc. and fem., resp.]). The amalgamated form "@" is employed only in connection with certain, typically informal, types of text or forms as an easy short hand ${ }^{10}$, but it is not accepted by the Royal Spanish Academy. In this paper only type a) of the dual forms is considered, as the graphically conspicuous forms b) and c) would have immediately revealed the real aim of the study to the informants.

\subsection{What is "gender neutrality"?}

In the former section the term "gender neutral" was defined on morpho-syntactic grounds, but as the task of this paper is to examine how certain words are interpreted as to their generic content (i.e. does a gender-neutral word convey gender-neutral meaning?) we are in need of a cognitively based definition of gender neutrality. As no well-established definition exists, I will explore two interpretations of the concept "gender neutrality" that have crucial impact on the analysis of the data.

From the point of view of a single language user, a sentence like Yesterday I met two doctors can be interpreted in three ways: 1) the doctors are two women, 2) the doctors are two men, or 3 ) the doctors each have a different gender. In such a scenario, only 3) would generally be ascribed a gender-neutral interpretation and, mathematically speaking, the gender neutrality of that interpretation would be $100 \%$. In the other two cases, the gender neutrality of two doctors would be $0 \%$ due to the fact that the sentences are interpreted gender-specifically (and thus not gender-neutrally at all). However, it is possible to see this matter from another angle, namely from the point of view of the speech community as a whole (which, in theory, consists of two or more people). Let us assume that by hearing the sentence Yesterday I met two doctors, exactly 50 out of 100 people would think of female doctors and exactly 50 would think of males. In this case, every respondent interprets the expression gender-specifically but, seen from the point of view of the entire speech community, the phrase two doctors is

these are not real gender neutral words. For a discussion and further examples, see Nissen (2002: 256f.). It should also be observed that invariable Spanish words like periodista ('journalist') or comunista ('communist') do not belong to the gender neutral group although on the surface they may seem to. In the majority of the cases in real texts, these words are combined with modifying determiners or adjectives (e.g. $\underline{\text { el }}$ comunista vs. $\underline{\text { la }}$ comunista ['communist', \{masc. and fem., resp.\}]; periodistas malos vs. periodistas malas ['bad journalists', \{masc. and fem., respectively\}]) and, therefore, in general, when used generically for both men and women, these words behave exactly as the masculine words that refer to human beings.

${ }^{8}$ Unfortunately, neither English nor Spanish have any established, agreed upon term for what is called a "dual form" here. For English "gender-inclusive" (Henley/Abueg (2003: 431) and "gender-balanced" (Gygax et al., 2008: 466) have been used and for Spanish desdoblamiento and reduplicación (Real Academia Española, 2009: 47). Also the term dobletes appears in the literature (e.g. García Meseguer, 1994: 95). (In German the term Beidnennung, 'the naming of both', is used).

9 No unanimous agreement exists about how many determiners should be used in front of dual forms. The Ministry of Education and Science in Spain (Ministerio ... 1998: 6) recommends one determiner only, e.g. Los profesores y profesoras... (which implies, as the masculine term usually stands alone, in the majority of cases the masculine article), whereas the recommendations published by UNESCO suggests using two determiners, one before each of the nouns; e.g. Los profesores y las profesoras... (1990: 20f.). Because my Spanish informants in the first study vehemently rejected the last option because it seemed strange, and because I did not want to introduce any alterations whatsoever in the questionnaires in the new study, I was forced to adhere to the use of only one masculine determiner, although (interestingly) the rejection may not have been as vehement as ten years before.

${ }^{10} \mathrm{Cf}$. the German so-called "Binnen-I" which also is an amalgamated form of a slash and an $i$, e.g. die LehrerInnen instead of die Lehrer/innen. 
interpreted gender-neutrally because the speech community as a whole does not decide unanimously whether two doctors refers to females or males. If we were asked how the (gender-) interpretation of two doctors was done in this speech community, we would have to respond that the interpretation is very balanced, i.e. not gender biased at all. Another more realistic example may further explain the consequences of this approach. If 60 out of 100 persons connect doctors with females, and 40 connect doctors with males, then 40 from each group neutralise each other and the difference (i.e. $60-40=+20$ ), can be interpreted as a gender-bias score of $+20 \%$; in this case the bias is towards females. For our study, this means that the difference between "female" and "male" scoring will be taken as an indication of a bias towards one specific gender, such that a score close to 100 indicates an absolute bias towards one gender, while a score close to zero will be an indication of gender neutrality (i. e. equally many people that think gender-specifically think of males and females). The implications these choices have for the analysis of our data will be presented in section 6 .

From this perspective, it seems justifiable to analyse the result as an instance of neutralisation of the gender in question, although each individual person in the community held a genderspecific interpretation. This means that the definition of gender neutrality crucially depends on whether or not our data is analysed 1) from the point of view of the individual language user, or 2) from the point of view of a speech community. In this article the latter definition will be employed.

This approach differs from others where gender neutrality refers to a situation in which people do not assign gender at all. Thus, it is possible (but still untested) that, for instance, the English sentence "The doctors treated the patient with anti-depressive medicine." renders an image of some kind of medical-related activity and does not evoke at all a clear male or female representation. Furthermore, and theoretically, an image of some androgynous creature could be evoked, although this too could be regarded as an instance of gender neutrality. ${ }^{11}$ For this investigation, however, we will follow the definition mentioned above, as the design of the study (by supplying specific first names in the singular) forces the respondent to think of concrete, individual persons.

\section{Goals of the investigation}

The present investigation replicates a study that was carried out in 1995 . While some results from this survey turned out to be rather surprising (cf. Nissen 1997), one objective of the present study was to confirm the data of the original. As a result, some of the goals of this study will necessarily be the same as the original one. These goals will be referred to as goal 1. However, the new data permit the comparison of information from respondents within a time span of ten years and thus an analysis of the extent to which the associations of specific words and expressions may have changed over the course of time. Thus, goal 2 refers to the analyses that explicitly compare the two surveys.

\subsection{Goal 1}

The first survey was based on Spanish recommendations for a non-sexist language, especially on the first recommendations published in 1988 by the Ministry of Education and Science (Ministerio ... 1988). Given that these recommendations proposed to use either gender neutral or dual forms in order to avoid the masculine forms, the present survey distinguishes between the following three types: type A (masculine form; e.g. Los alumnos... 'The students...' [masc.]), type B (gender neutral form; e.g. El alumnado... 'The student body...' [masc.]) and type C (dual form; e.g. Los alumnos y alumnas... 'The students [masc.] and students [fem.]'...) (cf. section 2.1.).

\footnotetext{
${ }^{11}$ As far as I know, until now no empirical investigation has ever dealt with these questions.
} 
The recommendations to avoid certain expressions and to favour others imply a range of assumptions with respect to the connection between particular word forms and the associations these forms evoke mentally, e.g. biased thinking. These implicit assumptions have been translated into the following four hypotheses that this study aims to test:

1. Texts containing masculine forms exhibit a distinct bias towards an association with maleness.

2. Texts containing gender neutral forms do not exhibit any gender bias.

3. Texts containing dual forms do not exhibit any gender bias either.

4. If any differences as to the gender neutrality should occur between gender neutral forms and dual forms, then dual forms are seen as being more gender neutral than gender neutral forms.

As the two surveys are not interdependent, the four hypotheses will be analysed separately and, thus, this analysis will contribute to the clarification of the link between linguistic expression and mental representation. Section 3.2 will focus on how this link has developed over time.

\subsection{Goal 2}

The second goal of this investigation intends to clarify whether or not changes in the interpretation of certain expressions have occurred over time and whether or not these changes are still in line with the intentions of the original recommendations. Hence, it was necessary to use the same items as were used ten years ago. One crucial claim put forward by adherents of recommendations for a gender-fair language is that the masculine form when used as a presumed gender-neutral form hides women and renders them invisible in everyday written and spoken discourse. It seems justified to ask, then, if women have become more visible over the course of time. Therefore, the question as to whether or not the intention of the recommendations for a gender-fair language (as discussed in section 1) have been fulfilled can be divided into two sub-questions: 1) is there a stronger bias towards gender-neutrality in 2005 than in 1995 and 2) have specific linguistic forms increased a bias towards female during the time span of 10 years?

By taking into consideration the three types of forms listed above, we can translate these questions more specifically into the following hypotheses:

5. From 1995 to 2005 the bias towards gender-neutrality will increase when respondents are exposed to texts containing either gender neutral or dual forms.

6. From 1995 to 2005 the bias towards gender-neutrality will neither increase nor decrease when respondents are exposed to texts containing the masculine forms.

7. From 1995 to 2005 the female bias will increase when respondents are exposed to texts containing dual forms.

8. From 1995 to 2005 the female bias will neither increase nor decrease when respondents are exposed to texts containing masculine or gender neutral forms.

\section{$4 \quad$ Design of the test}

As the aim of this study is to test the way in which certain word forms evoke mental representations in the reader of women, men or both, three distinct questionnaire types were designed that correspond to form type $\mathrm{A}, \mathrm{B}$ and $\mathrm{C}$ as mentioned in section 3.1. After the respondents responded to certain text sentences in the questionnaire, the gender associations they made should be evident. For this reason, the study was based on a blind test that 
contained a credible cover story that would simultaneously prevent the respondents from guessing the real aim of the survey. The introductory text of the questionnaire, therefore, leads the respondents to believe that the survey's aim is to investigate a correlation between certain first names and certain human characteristics or activities. In order to exemplify this correlation, the text informs the respondents that, in Danish, it is not unusual for people to assume that a boy named "Brian" is a very recalcitrant, disobedient child. In this way - by assuming that certain names in fact could be connected to certain characteristics or activities the respondents were invited to write down which first names they would associate with the characteristics or activities mentioned in each sentence of the questionnaire. ${ }^{12}$

Each questionnaire contained twelve different sentences. For each sentence, the respondents were required to insert two first names into the spaces indicated. To ensure that the respondents associated the situations described in the sentences with two disconnected individuals (i.e. not married), it was important to formulate each sentence so that it fostered specific associations about the two names.

Furthermore, while editing the actual wording of the twelve sentences, pains were taken to avoid stereotypical thinking with regard to gender roles. Sentences were chosen that refer to real-life situations in which an equal distribution of women and men is found. The nouns used in the type A questionnaire were the following: los profesores 'the teachers', los interesados 'the interested (ones), los funcionarios 'the civil servants', los alumnos 'the pupils', los damnificados 'the victims', los empleados 'the employee', los ciudadanos 'the citizens', los chicos 'the youngsters', los niños 'the children', los defensores 'the defenders', los españoles 'the Spaniards', los ingenieros 'the engineers'. The type B questionnaires contained corresponding gender neutral nouns (e.g. el profesorado 'the teacher staff'), and type C questionnaires contained obvious corresponding dual forms.

A basic question that had to be resolved was whether or not to use singular or plural nouns. To the best of my knowledge, no investigation exists that examines which of the two forms is more generic than the other with respect to sex. It was decided to use the plural form (preceded by the Spanish determiner los 'the') because the singular form would have been incompatible with the basic idea to supply each sentence with two names - a procedure that necessarily leads to an association with plurality. ${ }^{13}$ Finally, any pronominal reference of the tested form in question had to be strictly avoided.14

To illustrate, one of the twelve sentences from the questionnaires is reproduced below (in this case type A containing the masculine form, i.e. los interesados):

Cuando leyeron: "Los interesados deben hacer llegar su curriculum vitae a la dirección señalada en el reverso de este documento (añadir nombre:). $y$ (añadir nombre:) decidieron no solicitar el puesto porque la empresa no estaba situada en la capital en la que vivían.

\footnotetext{
12 Although this cover story may appear rather farfetched, there is little doubt that some relationship may exist between first names and peoples' conduct. Advertising companies, at least in France, use first names for direct mail advertising ('prénom scoring'). This technique indicates that first names and consumer behaviour are somehow related (cf. the Danish newspaper Børsen, 6.2.1995, p. 8). Judging from the amount of space left open for comments, no respondent seems to have discovered the real aim of the surveys.

13 Although, due to the design of my investigation, I will focus only on the masculine plural form, it is worth pointing out that the masculine singular form does not unequivocally refer to a male being either. Also in this case, the reference can be interpreted either as specific (to a male) or as generic (e. g. En España el obrero tiene que trabajar duramente. 'In Spain the worker has to work hard.'). Interestingly, a very recent study that appeared after finishing this article points towards considerable differences of the "generic" interpretation of singular and plural forms in Dutch and German (De Backer/De Cuypere 2012).

${ }^{14}$ In a comparable study for German, Klein (1988) realised that when analysing the results, there was a test sentence that contained an anaphoric er ('he'). This sentence scored (not surprisingly) the highest rate of "male bias" (1988:315).
} 
[When they read: "The interested [masc.] (ones) have to send their curriculum to the address indicated on the reverse side of this document (add first name:) and (add first name:) capital where they were living.] decided not to apply for the job because the business was not in the

In the two other types of questionnaires, type $\mathrm{B}$ and $\mathrm{C}$, the phrase los interesados was substituted with the gender neutral expression las personas interesadas ('the interested persons') for type B and with the dual form los interesados $y$ interesadas ('the interested [masc.] and interested [fem.] ones') for type C.

\section{$5 \quad$ Method}

In accordance with the three different types of forms (masculine, gender neutral and dual), the three surveys and questionnaires will be referred to as survey $\mathrm{A}, \mathrm{B}$ and $\mathrm{C}$ and questionnaire $\mathrm{A}$, $\mathrm{B}$ and $\mathrm{C}$.

\subsection{Participants}

Both surveys $(1995,2005)$ were conducted at three different universities in Spain and the students were given one of the questionnaires (either type A, B or C) without knowledge of the existence of the other types. The linguistic form according to the number of respondents is shown in Table 1. The distribution is very balanced: each form was given to one-third of all respondents and this distribution holds for both surveys. However, in the 2005 survey, there was an additional 70 respondents. It should be observed that three out of four respondents were women. Unfortunately the data are too few to draw statistically valid conclusions based on gender in all cases. For this reason, the data will not be presented "genderwise".

\begin{tabular}{|c|c|c|c|c|}
\cline { 2 - 5 } \multicolumn{1}{c|}{} & \multicolumn{2}{c|}{1995} & \multicolumn{2}{c|}{2005} \\
\hline Linguistic form & Number & $\mathbf{\%}$ & Number & \% \\
\hline Masculine & 66 & $\mathbf{3 3 . 7}$ & 92 & $\mathbf{3 4 . 5}$ \\
\hline Gender neutral & 67 & $\mathbf{3 4 . 2}$ & 81 & $\mathbf{3 0 . 5}$ \\
\hline Dual & 63 & $\mathbf{3 2 . 1}$ & 93 & $\mathbf{3 5 . 0}$ \\
\hline Total & 196 & $\mathbf{1 0 0}$ & 266 & $\mathbf{1 0 0}$ \\
\hline
\end{tabular}

Table 1: Linguistic form according to number of respondents

\subsection{Procedure}

The distribution of the questionnaires differed slightly in the two surveys. As the intention of the 1995 survey was not just to reach young students, but also elderly respondents, students at one university were given several questionnaires - one for themselves and the rest for elderly family members at home. For this reason, the study from 1995 contains respondents over 25 years of age. For the sake of consistency in comparisons, however, only data from students aged 17 to 25 years were extracted from the 1995 study and, therefore, roughly one-third of the questionnaires of the 1995 study had to be eliminated. ${ }^{15}$ As mentioned in section 4, each sentence of the questionnaire left two spaces to allow two first names to be filled in. The data were registered on a spread sheet for each survey according to the following procedure: two female names were registered as "female", two male names as "male" and one female and one male name, or one male and one female name, were registered as "mixed". ${ }^{6}$ Only the cases

\footnotetext{
15 This procedure explains why the data presented here and the data from Nissen (1997) differ.

16 No pains were taken to consider whether or not a female name $(=\mathrm{f})$ or a male name $(=\mathrm{m})$ occupied the first place or vice versa. In both cases, the decision to insert both a female and a male name supposes a gender-neutral representation no matter which gender came to the respondents' minds first. For the sake of documentation, the actual distribution was as follows:
} 
where the respondents filled in both spaces were counted and very few had to be excluded due to illegibility. Seven answers had to be excluded because an unambiguous gender assignment was not possible; for example, Pepi and Berni had to be excluded as Pepi can refer to both Pepe [masc.] and Pepa [fem.] and Berni to both Bernardo [masc.] and Bernarda [fem.].

\section{$6 \quad$ Results}

\subsection{Goal 1: Interpretation of masculine, gender neutral and dual forms}

Tables 2 and 4 below show the results based on the respondents' interpretations of gender (i.e. female, male, or mixed) according to the three types of forms. The columns are derived from pure summations, and the subsequent calculations are in percentages denoting the actual occurrences of first names. For example, the first row in table 2 shows that a total of 371 sentences in the form that contained only masculine words were filled with one female and one male name; in percentages, the "mixed" reading thus scores $47.8 \%$. Tables 3 and 5 show the overall gender bias according to the types of forms (and according to the procedure and the definition discussed in section 2.2.). The higher the score, the higher the bias is towards one gender. The numbers given in these two tables are reached by first eliminating all "mixed" occurrences (as these, naturally, cannot count as gender biased), then calculating the distribution in percentages. The last column is then reached by subtracting the "female" occurrences from the "male" ones. A minus sign indicates a male bias, a plus sign a female bias.

\begin{tabular}{|l|c|c|c|c|c|c|}
\hline Linguistic form & \multicolumn{2}{|c|}{ mixed $^{\#}$} & \multicolumn{2}{c|}{ female $^{\#}$} & \multicolumn{2}{c|}{ male $^{\#}$} \\
\hline & Number & $\%$ & Number & $\%$ & Number & $\%$ \\
\hline Masculine & 371 & $\mathbf{4 7 . 8}$ & 171 & $\mathbf{2 2 . 0}$ & 235 & $\mathbf{3 0 . 2}$ \\
\hline Gender neutral & 378 & $\mathbf{4 7 . 7}$ & 172 & $\mathbf{2 1 . 7}$ & 243 & $\mathbf{3 0 . 6}$ \\
\hline Dual & 410 & $\mathbf{5 4 . 6}$ & 179 & $\mathbf{2 3 . 8}$ & 162 & $\mathbf{2 1 . 6}$ \\
\hline
\end{tabular}

Table 2: Mixed, female, male bias according to linguistic form (1995) ${ }^{\#}$ Chi2(4) $=20.27$ and $P=0.000^{17}$

\begin{tabular}{|l|c|c|c|c|c|}
\hline Linguistic form & \multicolumn{2}{|c|}{ female } & \multicolumn{2}{c|}{ male } & gender bias $^{\# \#}$ \\
\hline & Number & $\%$ & Number & $\%$ & $\%$ \\
\hline Masculine & 171 & $\mathbf{4 2 . 1}$ & 235 & $\mathbf{5 7 . 9}$ & $\mathbf{- 1 5 . 8}$ \\
\hline Gender neutral & 172 & $\mathbf{4 1 . 4}$ & 243 & $\mathbf{5 8 . 6}$ & $\mathbf{- 1 7 . 1}$ \\
\hline Dual & 179 & $\mathbf{5 2 . 5}$ & 162 & $\mathbf{4 7 . 5}$ & $\mathbf{+ 5 . 0}$ \\
\hline
\end{tabular}

Table 3: Gender-bias according to linguistic form, mixed responses removed (1995)

${ }^{\#}$ Chi2(2) = 9.27 and P = 0.0097; "+" indicates "female bias"; "-" indicates "male bias"

The results from an analysis of the data from the 1995 survey are as follows:

For the masculine form, Table 2, row 1, shows that this form does not necessarily lead to a mental representation of "male". In fact, this only occurred in less than one-third $(=30.2 \%)$ of

Survey 1995: type A f+m: $20.2 \%$ and $\mathrm{m}+\mathrm{f}: 27.5 \%$, type B $\mathrm{f}+\mathrm{m}: 23.0 \%$ and $\mathrm{m}+\mathrm{f}: 24.6 \%$, type $\mathrm{C}+\mathrm{f}$ : $28.23 \%$ and $\mathrm{m}+\mathrm{f}: 26.36 \%$.

Survey 2005: type A f+m: $21.3 \%$ and $\mathrm{m}+\mathrm{f}: 23.5 \%$, type B $\mathrm{f}+\mathrm{m}: 22.5 \%$ and $\mathrm{m}+\mathrm{f}: 24.3 \%$ and type C: $\mathrm{f}+\mathrm{m}: 22.7 \%$ and $\mathrm{m}+\mathrm{f}: 21.5 \%$.

In the questionnaires containing dual forms (= type C), there is, in both surveys, a higher percentage of the ordering female first. This could lead to the conclusion that more respondents initially thought of women when exposed to the dual form.

17 The probability value (where $\mathrm{P}<0.005$ means that the data is not arbitrary) presupposes that the respondents completed the test sentences independently from each other. The reasonableness of this assumption rests upon the fact that it seems unlikely that a respondent would have completed e.g. sentence 4 in a certain way because 
all sentences. With respect to mixed answers, we observe that in almost half of the cases (= $47.8 \%$ ), people connect the masculine form with both females and males, i.e. in approximately half of the cases this form was considered to be a gender-neutral term. Thus, in roughly every second case, the masculine form functions as a generic form. Interestingly, despite its form, in almost one-fifth of the sentences $(=22.0 \%)$, the masculine form was connected to "female" only. There is definitely no clear connection between one form and one interpretation. On the other hand, after having eliminated all mixed occurrences and balanced the "male" and "female" representations in table 3, we observe a bias towards "male" for the masculine form $(=-15.8 \%)$. The use of the masculine form indeed results in a bias towards a male interpretation, although many individuals as such did not make this connection. Altogether, our first hypothesis is supported since there is a distinct bias of $15.8 \%$.

With regard to the gender neutral form, Table 2, row 2, there is considerable similarity between the interpretation of this form and the masculine form. Thus the neutral form does not ensure a neutral reading. Table 3 reinforces this result. Contrary to my hypothesis, the data reveal a gender bias towards male $(-17.1 \%)$ which is greater than that for the masculine form. On these grounds, the second hypothesis is rejected.

With respect to the dual form, Table 2, row 3, we observe, in comparison with the masculine and the gender neutral forms, that the mixed answers increased by approximately $7 \%$ to $54.6 \%$; thus the dual form seems the best candidate for a gender-neutral interpretation. However, in $45.4 \%(=23.8+21.6)$ of cases, this form was interpreted with reference to either males or females exclusively. These interpretations mean that, despite the fact that the text makes explicit reference to both females and males (by means of the dual form), this procedure does not prevent a gender-specific reading. When we look at Table 3 , row 3 , we encounter the lowest gender-bias score so far, as it has now decreased to only $5 \%$. Our third hypothesis, which predicted no gender bias for the dual forms, therefore, comes very close to being supported. A further interesting finding is that with dual forms, the gender-bias score has been reversed, meaning that the bias is now towards females.

A comparison of the dual and gender neutral forms not only reveals that the mixed interpretation is higher for the dual form, but also that the gender-bias score is lower. Therefore, the dual form strives to create a more gender-neutral reading than the gender neutral form. The prediction of the fourth hypothesis coincides with this finding.

The fact that so many respondents, despite the form given to them, chose a gender-specific reading and the fact that the differences between the forms were not profound was a rather surprising finding in the 1995 study. Therefore, replicating the survey in order to chart any changes in the findings seemed obvious. The data of the replicated survey from 2005 are presented in Table 4 and 5.

she filled the gaps in a specific way in, e.g. sentence 2 . This occurrence would imply that the test sentences were somehow connected - which they were not. 


\begin{tabular}{|l|c|c|c|c|c|c|}
\hline Linguistic form & \multicolumn{2}{|c|}{ mixed $^{\#}$} & \multicolumn{2}{c|}{ female $^{\#}$} & \multicolumn{2}{c|}{ male $^{\#}$} \\
\hline & Number & $\%$ & Number & $\%$ & Number & $\%$ \\
\hline Masculine & 494 & $\mathbf{4 5 . 6}$ & 293 & $\mathbf{2 6 . 9}$ & 299 & $\mathbf{2 7 . 5}$ \\
\hline Gender neutral & 454 & $\mathbf{4 8 . 6}$ & 214 & $\mathbf{2 2 . 9}$ & 266 & $\mathbf{2 8 . 5}$ \\
\hline Dual & 493 & $\mathbf{4 5 . 3}$ & 335 & $\mathbf{3 0 . 8}$ & 260 & $\mathbf{2 3 . 9}$ \\
\hline
\end{tabular}

Table 4: Mixed, female, male bias according to linguistic form (2005)

${ }^{\#}$ Chi2(4) $=17.56$ and $P=0.002$

\begin{tabular}{|l|c|c|c|c|c|}
\hline Linguistic form & \multicolumn{2}{|c|}{ female } & \multicolumn{2}{c|}{ male } & gender bias $^{\# \#}$ \\
\hline & Number & $\%$ & Number & $\%$ & $\%$ \\
\hline Masculine & 293 & $\mathbf{4 9 . 5}$ & 299 & $\mathbf{5 0 . 5}$ & $\mathbf{- 1 . 0}$ \\
\hline Gender neutral & 214 & $\mathbf{4 4 . 6}$ & 266 & $\mathbf{5 5 . 4}$ & $\mathbf{- 1 0 . 8}$ \\
\hline Dual & 335 & $\mathbf{5 6 . 3}$ & 260 & $\mathbf{4 3 . 7}$ & $+\mathbf{1 2 . 6}$ \\
\hline
\end{tabular}

Table 5: Gender-bias according to linguistic form, mixed responses removed (2005)

${ }^{\# \#} \mathrm{Chi} 2(2)=11.38$ and $\mathbf{P}=\mathbf{0 . 0 0 3 4}$; "+" indicates "female bias", "-" indicates "male bias"

As can be seen from Table 4, the findings have changed from those of the 1995 survey, as all instances of the "mixed" category have decreased slightly. This indicates, again, that no matter which form is used, the respondents in 2005 tended to "think" more in terms of a gender-specific representation (in fact, even more so than in the older study). Furthermore, the 2005 study indicates that there is no direct connection between the linguistic form and the mental representation as such. Table 5, in which the 'mixed' answers were eliminated shows an interesting finding that runs contrary to the first hypothesis: the overall gender-bias for the masculine form is almost perfectly balanced in 2005 (i.e. there is only a small bias of 1\%). For this reason, seen from the entire population as a whole, the masculine form does not appear to be male-biased; instead, compared to the gender neutral and the dual form, this form appears to be the best candidate for a gender-neutral interpretation.

The second hypothesis is also rejected: though the gender neutral form scores a little higher with respect to "mixed" answers (48.6\%, Table 4), this form, at the same time, demonstrates a strong bias towards male $(=-10.8 \%$, Table 5). Surprisingly, as in the 1995 survey, this form once again shows a stronger male bias than the masculine form.

The third hypothesis predicted no gender bias with respect to dual forms, but, although the "mixed" score is very high $(=54.6 \%$, Table 4$)$, the dual form at the same time shows a strong gender bias with respect to the gender-specific interpretation; in fact, it is the highest bias score in this survey $(=+12.6 \%$, Table 5). Therefore, the third hypothesis cannot be supported.

The fourth hypothesis cannot be supported either; the dual form is no better in regard to gender neutrality than the gender neutral form. Not only does the gender neutral form override the dual form with regard to "mixed" answers (48.6\% and $45.3 \%$ resp., Table 4), but also with respect to gender bias, the dual form turns out to be a weaker candidate (-10.8 and +12.6 , resp., Table 5). As a matter of fact, the gender neutral form shows a slightly more balanced behaviour as to gender neutrality than the dual form; in other words, the dual form shows a decline in gender neutrality.

Altogether, for the 2005 survey none of the four hypotheses could be confirmed. These findings run contrary to the survey from 1995 where only the second hypothesis was rejected.

\subsection{Goal 2: Comparison of the 1995 and 2005 surveys}

The second goal of the current study, which partly triggered the replication of the first survey, was to investigate the possible changes in interpretation that might have occurred over a 
period of 10 years. By comparing the data presented above, we see some interesting findings emerge.

By using the same data as presented in Tables 3 and 5, Table 6 compares the extent of gender bias between 1995 and 2005, showing only the bias towards males (= "-") or females (= "+") of those respondents that had chosen "gender-specific thinking" (i.e. had chosen to fill in two male names or two female names).

\begin{tabular}{|l|c|c|}
\hline Linguistic form & $\mathbf{1 9 9 5}^{\#}(=$ Table 3) & $2005^{\# \#}(=$ Table 5) \\
\hline Masculine & -15.8 & -1.0 \\
\hline Gender neutral & -17.1 & -10.8 \\
\hline Dual & +5.0 & +12.6 \\
\hline
\end{tabular}

Table 6: Gender bias according to linguistic form; 1995 and 2005 compared (in \%)

${ }^{\#}$ Pearson chi2 $(2)=9.27$ and $P=0.0097$; '"-" indicates "male bias";

\#\# Pearson chi2(2) = 11.38 and $P=0.0034 "+"$ indicates "female bias"

The fifth hypothesis predicted that the bias towards a gender-neutral interpretation would increase for both the gender neutral and the dual forms. However, this prediction is only valid for the gender neutral form where the gender bias has fallen (from $-17.1 \%$ to $-10.8 \%$ ). The gender bias of the dual form, in contrast, has risen (from $+5.0 \%$ to $+12.6 \%$ ), so this form has become less gender neutral than 10 years earlier.

According to the sixth hypothesis, the bias towards a gender-neutral interpretation would not change with respect to the masculine forms. But in the 2005 survey we observe a dramatic change: the gender-bias score of the masculine form has decreased by $14.4 \%$ and now appears to be almost devoid of gender bias. This decrease means that the masculine form in $2005-$ against all odds - appears to be the best candidate for gender-neutral expression out of the three forms analysed.

The seventh and eighth hypotheses were concerned with female bias. The data that focus on the corresponding "female bias" are presented in Table 7. Male bias and female bias are strictly interdependent (male bias can be expressed by "100-x", where $\mathrm{x}$ is a number in the table). As in Table 6, all "mixed" answers have been excluded from the calculations (as these, by nature, do not focus on one specific gender).

\begin{tabular}{|l|c|c|}
\hline Linguistic form & $\mathbf{1 9 9 5}^{\#}$ (= Table 3) & 2005 $^{\# \#}$ (= Table 5) \\
\hline Masculine & 42.1 & 49.5 \\
\hline Gender neutral & 41.5 & 44.6 \\
\hline Dual & 52.5 & 56.3 \\
\hline
\end{tabular}

Table 7: Female bias according to form; 1995 and 2005 compared (in \%)

${ }^{\#}$ Chi2(2) $=9.27$ and $P=0.0097,{ }^{\# \#}$ Chi2(2) $=11.38$ and $P=0.0034$

Table 7 must be read as follows. For instance, with respect to row one, column one: of all respondents that in 1995 chose a gender-specific interpretation, $42.1 \%$ demonstrated female bias when exposed to texts that contained the masculine forms.

According to our seventh hypothesis, we would expect an increase of female bias when respondents are exposed to texts containing dual forms over time. Indeed, this is the case; female bias increased by $3.8 \%$ (from $52.5 \%$ to $56.3 \%$ ). The seventh hypothesis is thus supported. The eighth hypothesis, however, predicted no change with respect to neither the masculine nor the gender neutral form, but in both cases female bias increased, too $(7.4 \%$ and $3.1 \%$, respectively). Interestingly, the greatest change occurred with respect to the masculine form. Hence, the eighth hypothesis has been rejected.

The conclusion one must draw is that no matter which form is employed; female bias has increased over the last ten years. At the same time, however, it is worth noting that the form 
that most readily ensures "the visibility" of women was, and still is, the dual form. In both surveys, this form was the best candidate to convey female bias, i.e. in over $50 \%$ of the cases.

To conclude this section, it may be worth pointing out that the data, as a whole, suggest a tendency for the respondents to have become less polarised over the time span of ten years, although this tendency is not statistically significant. This means that the respondents in 2005, as a whole, seem to agree with each other more in their interpretations than the respondents did in 1995.

\subsection{Results of female respondents}

This investigation, as described in the introduction, does not deliver statistically significant results for women and men separately. However, a few results in relation to women's linguistic behaviour are, in fact, statistically significant and only these results will be dealt with in this section. Thus, in tables $8-11$, only female respondents have been taken into consideration. (Unfortunately, due to the relatively few number of men that participated in both surveys, no concluding observations are possible for this group).

\begin{tabular}{|l|c|c|c|c|c|c|}
\hline Linguistic form & \multicolumn{2}{|c|}{ mixed $^{\#}$} & \multicolumn{2}{c|}{ female $^{\#}$} & \multicolumn{2}{c|}{ male $^{\#}$} \\
\hline Masculine & Numer & $\%$ & Number & $\%$ & Number & $\%$ \\
\hline Gender neutral & 317 & 46.5 & 161 & 23.6 & 204 & 29,9 \\
\hline Dual & 334 & 49.5 & 154 & 22.9 & 186 & 27,6 \\
\hline
\end{tabular}

Table 8: Mixed, female and male bias according to linguistic form in 1995 (female respondents only) ${ }^{\#}$ Chi2(4) $=19.79$ and $P=0.001$

\begin{tabular}{|l|c|c|c|c|c|c|}
\hline Linguistic form & \multicolumn{2}{|c|}{ mixed $^{\#}$} & \multicolumn{2}{c|}{ female $^{\#}$} & \multicolumn{2}{c|}{ male $^{\#}$} \\
\hline & Number & $\%$ & Number & $\%$ & Number & $\%$ \\
\hline Masculine & 469 & 46.2 & 282 & 27.8 & 264 & 26.0 \\
\hline Gender neutral & 338 & 49.4 & 181 & 26.5 & 165 & 24.1 \\
\hline Dual & 445 & 46.2 & 203 & 32.7 & 315 & 21.1 \\
\hline
\end{tabular}

Table 9: Mixed, female, male bias according to linguistic form in 2005 (female respondents only) ${ }^{\#}$ Chi2(4) $=12.73$ and $P=0.013$

Tables 8 and 9 show that the distribution of 'mixed' is similar in both periods with respect to the masculine and gender neutral forms. The interpretation of the dual form, however, has changed considerably (from 54.9 to $46.2 \%$ ). With respect to a female reading, the tables show an increase with all forms and a subsequent decrease for the male reading. Only the dual form behaves differently as both the female and the male reading is increased in 2005 .

An unexpected finding also shows up with respect to the gender bias after eliminating "mixed" responses:

\begin{tabular}{|l|c|c|c|c|c|}
\hline Linguistic form & \multicolumn{2}{|c|}{ female } & \multicolumn{2}{c|}{ male } & gender bias $^{\# \#}$ \\
\hline & Number & $\%$ & Number & $\%$ & $\%$ \\
\hline Masculine & 161 & 44,1 & 204 & 55,9 & -11.8 \\
\hline Gender neutral & 154 & 45,3 & 186 & 54,7 & -9.4 \\
\hline Dual & 150 & 56,8 & 114 & 43,2 & +13.6 \\
\hline
\end{tabular}

Table 10: Gender-bias without "mixed" according to linguistic form in 1995 (in percent, female respondents only); ${ }^{\# \#}$ Chi2(2) $=10.51$ and $P=0.0052$; "-" indicates "male bias"

\begin{tabular}{|l|c|c|c|c|c|}
\hline Linguistic form & \multicolumn{2}{|c|}{ female } & \multicolumn{2}{c|}{ male } & gender bias $^{\# \#}$ \\
\hline & Number & $\%$ & Number & $\%$ & $\%$ \\
\hline Masculine & 282 & 51,6 & 264 & 48,4 & +3.3 \\
\hline Gender neutral & 181 & 52,3 & 165 & 47,7 & +4.6 \\
\hline
\end{tabular}




\begin{tabular}{|l|l|l|l|l|l|}
\hline Dual & 203 & 39.2 & 315 & 60,8 & +21.6 \\
\hline
\end{tabular}

Table 11: Gender-bias without 'mixed' according to linguistic form in 2005 (in per cent, female respondents only); ${ }^{\# \#} \mathrm{Chi} 2(2)=13.31$ and $\mathrm{P}=0.0013$; "-" indicates "male bias", "+" indicates "female bias"

Tables 10 and 11 show that while the bias for at least the masculine and the gender neutral forms in 1995 was in favour of male, in 2005 these forms, surprisingly, render the opposite interpretation. This means that the female respondents 10 years after the first survey more readily connect the masculine and the neutral gender form with their own gender and this is especially the case with the dual form: when interpreting this form, women score the highest gender bias of both surveys $(=+21.6 \%)$. This means that if the female respondents connected the dual forms with a specific gender, then approximately every fifth respondent had specifically a female interpretation in their minds. This is, naturally, surprising given the fact that the sentences by means of the dual forms made explicit reference to both genders.

Another interesting finding that merits comment has to do with the connection between the linguistic form and one's own gender. Although no statistically significant data are available, there seems to be a much stronger tendency for men to connect the three forms with their own gender. Thus, men seem to behave more "gender-centric" than women. This result, however, awaits further investigation.

\section{$7 \quad$ Discussion}

\subsection{Discussion of results}

Before we review the results of the investigation as a whole, two aspects should be kept in mind. First, operating with a rigorous definition of what is understood by "gender neutrality" is essential. As discussed in the introduction, different perspectives, i.e. from the point of view of the individual speaker or from a speech community, will render very different results, perhaps even contradictory ones. Due to the fact that most recommendations were written to instruct producers of language who reach more than one addressee (publishers, editors, journalists, writers, etc.), it is justifiable to operate with a definition that takes into account the entire speech community as such. Secondly, it is worth remembering that - although the presented data are statistically significant - the data are, strictly speaking, only valid for the chosen group of respondents, i.e. university students between 17 and 25 years of age ${ }^{18}$. Consequently, the conclusions cannot be assumed to have general validity, especially as students may be more progressive in their attitudes and are subject to greater linguistic innovations. These considerations have, naturally, important implications for revisions of non-sexist guidelines.

Both surveys clearly demonstrate that there is no clear-cut correspondence between certain linguistic forms and the mental (gender-) representations evoked in peoples' minds. For instance, a masculine form is not automatically connected with a male image. However, significant variations with respect to the overall bias of the linguistic forms in question have emerged and as the linguistic forms were the only items that had been changed in the questionnaires, these interpretational variations must correlate with the specific forms. The investigation also shows that these variations significantly change over time; for example, a

18 The choice of type of informants (i.e. students) in this paper does not differ from that of most other studies mentioned in the bibliography but a population of this kind does not necessarily reflect the attitudes of the entire population. For this reason, the method employed by Koziar (2009) appears to be more fruitful in the future. She used a population of 225 participants that were selected so that the sample was equivalent to the population of the USA in race, income, gender and age. 
clear male bias of the masculine form almost seems to have vanished completely ten years after the first study.

With respect to our first four hypotheses, we must recognise that while in 1995 all but one of the hypotheses could be confirmed; in 2005 all of them were rejected. This was an unexpected outcome. In addition to the masculine form, as mentioned in the previous paragraph, the linguistic interpretation of the dual form was also unexpected.

By comparing the Spanish guidelines for a gender-fair language - that triggered the first survey in the first place - with the reported results, some interesting considerations emerge. Since the 1995 survey showed a distinct male bias of the masculine form, the vehement rejection of this form by the recommendations seems justified. In 2005, however, the masculine form shows almost no male bias. This finding not only runs contrary to the result from 1995, but also to the results found in many other studies. For example, Braun et al. found for German that "the inclusion of women is higher with non-sexist alternatives than with masculine generics" (2005: 1). Similar results as to gender-neutral terms were found in Brauer and Landry (2008). Whether or not the new results for Spanish are a language-specific phenomenon ${ }^{19}$, or whether or not the interpretations are generally changing, should be investigated further. At any rate, at present, the findings for Spanish mean that the recommendation to avoid the masculine form on the grounds of it being male biased cannot be supported statistically. On the contrary, in order to convey "gender-neutral thinking" one should promote the masculine form, as this form seems to be the best candidate for a genderneutral interpretation. At the same time, there are no convincing reasons to encourage the use of either the gender neutral or the dual forms if one intends to transmit a gender-neutral meaning. In fact, both forms exhibited a strong gender bias both in 1995 and in 2005: the gender neutral forms towards male, the dual forms towards female. Generally speaking, the question that was raised in section 3.2, "Do people think more gender-neutrally in 2005 than ten years before?" has to be answered both affirmatively and negatively, depending on the linguistic form in question: with respect to the masculine and the gender neutral form, the gender bias (towards male) has decreased, with respect to the dual form it has increased (towards female).

Another aim of the recommendations, namely to make women more visible in public discourse, was in 1995, and still is in 2005 , best achieved by means of the dual form, i.e. by explicitly referring to women. This result appears to be quite stable over time and was already found in earlier studies. A comparison of seven different investigations that were carried out between 1993 and 2004 for German (a language that like Spanish possesses grammatical gender) reached the following conclusion:

Most studies' results agree that masculine generics lead to a lesser inclusion of women than men in mental representations compared to linguistic alternatives that comprise feminine form. (Irmen/Roßberg, 2004: 274, my emphasis)

It is, therefore, justifiable to conclude that the explicit mention of women by means of linguistic forms that unmistakably refer to women facilitate speakers' mental representations of them. In other words, in order for women to become more visible, people should be reminded of their existence by means of unambiguous linguistic markers. In this context, however, one should not forget that the visibility has increased significantly within the investigated time span of ten years no matter which form was chosen. Even the masculine form experienced an increase with respect to a female bias; a fact that runs contrary to what was expected of the form in question. Our data also show that women most readily give a female interpretation if they think in gender-specific terms, i.e. connect to their own

${ }^{19} \mathrm{Cf}$. the results by Gygax et al. (2008). In this study differences as to the interpretation of the generic masculine form emerged even between languages that both possess grammatical gender (in this case French and German). 
gender (cf. section 6.3.). As we have seen, the use of the dual form boosts this interpretation considerably. There is little doubt that the answer to the second issue raised in section 3.2., whether women have become more "visible" in 2005 than they were in 1995, should be answered affirmatively.

The discussion of our data and their implications for the recommendations of a gender-fair language touches upon political issues linked with the position of women in society. If the aim is to promote female visibility, the dual form should definitely be chosen. On the other hand, if one favours gender neutrality, i.e. making reference to persons in a gender balanced way by evoking an equal amount of female and male images, then, surprisingly, the masculine form seems to be the best candidate. Determining which of these two options to choose depends on one's political stance and which political aims one pursues. It should also be observed that both procedures seem to be contextually interdependent. Gygax and Gabriel (2008: 149) found for French role names that a job description using only masculine forms will generally be considered less suitable for women, but even more so if other job advertisements make explicit references to both women and men.

This study cannot present any evidence about why the interpretations of these linguistic forms have changed. The recommendations have most likely had an effect, but not necessarily because people in general have rigorously complied with them, but because publishers, journalists, etc. have had to take a position that, more often than not, gave rise to discussions on this issue. ${ }^{20}$ At the same time, one must bear in mind that Spanish society has witnessed a tremendous change during the decade investigated as to the integration of women in the labour market, the educational system and the administrative sector; this change is still ongoing. Women have thus become more visible in public - and not only in public discourse. Definite answers to these questions will need investigations that explicitly correlate linguistic phenomena and societal changes.

With respect to the methodology of the present study, the (surprising) results have demonstrated the need for such an approach. For instance, Henley and Abueg conclude, on the basis of a comparison of 19 different empirical studies, that

There seems to be no need for more research on whether masculine forms can serve as true generics in English. The existing research is unequivocal on the question: they cannot. (2003: 449)

However, these studies were carried out between 1971 and 1999 and we cannot be sure if these findings would have been the same, if the empirical studies analyzed had been replicated years later by using exactly the same procedure. All the investigations that were compared and examined by Henley and Abueg (2003) (and also by Irmen and Roßberg (2004) mentioned above) differ in their methodological approach and, therefore, make direct comparisons impossible. This is not the case with replicated investigations and they appear to be one suitable means to provide us with data which shed light on the ways in which interpretations of certain linguistic forms change over time. What the present investigation definitely has shown is that these interpretations do not seem to be stable at all, but, instead, are subject to change over time.

\footnotetext{
${ }^{20}$ It should also be noted that the Royal Spanish Academy of Language (Real Academia Española 2012), in an announcement issued at the beginning of 2012, severely criticized the use of dual forms, mainly because they rendered texts illegible. A vehement discussion subsequently ensued and after weeks of debate and fierce reactions (mainly by women) in the mass media and a pro-manifesto supported by various prominent Spanish linguists, an interesting article was published by Morena Cabrera (2012) who claimed, on the basis of a systematic analysis of the original announcement, that the Spanish language academy had reacted on false linguistic grounds. These 2012 events happened too late to have been included in the main text of this article.
} 


\section{References}

Asociación Cultural Simone de Beauvoir (ed.) (2006): Guía para la utilización de un lenguaje no sexista. Torrejón de Ardoz: Ayuntamiento de Torrejón. Concejalía de la Mujer. http://cdd.emakumeak.org/ficheros/0000/0048/Gui\%CC\%81a_lenguaje_no_sexista.pdf, accessed February 13, 2013.

Ayuntamiento de Valladolid (1996): Plataforma por un Lenguaje no Discriminatorio. Alternativas para un lenguaje no discriminatorio. Valladolid: Ayuntamiento de Valladolid.

Bengoechea, Mercedes (2000): "Historia (española) de unas sugerencias para evitar el androcentrismo lingüístico". Revista Iberoamericana de Discurso y Sociedad 2/3: 33-58.

Brauer, Markus/Landry, Michaël (2008): "Un ministre peut-il tomber enceinte ? L'impact du générique masculin sur les représentations mentales". Année Psychologique 108/2: 243272.

Braun, Friederike/Sczesny, Sabine/Stahlberg, Dagmar (2005): "Cognitive effects of masculine generics in German: an overview of empirical findings". Communications 30: 1-22.

Cacciari, Cristina/Padovani, Roberto (2007): "Further Evidence of Gender Stereotype Priming in Language: Semantic Facilitation and Inhibition in Italian Role Nouns". Applied Psycholinguistics 28: 277-293.

Caja de ahorros El MONTE (2005): Manual de uso [NO sexista] del lenguaje. http://www.iesparquegoya.es/files/biblioteca/manual_no_sexista.pdf, accessed February 13, 2013.

Fernández Calero, Ángeles María (2006): "Creencias y actitudes lingüísticas en torno al género gramatical en español". In: Rodríguez, Sancho et al. (eds.) (2006): Estudios sobre lengua, literatura y mujer. Jaén, Universidad de Jaén: 235-285.

Fernández Calero, Ángeles María (2007): Percepción social de los sexolectos. Cádiz: Universidad de Cádiz.

De Backer, Maarten/De Cuypere, Ludovic (2012): "The interpretation of masculine personal nouns in German and Dutch: a comparative experimental study". Language Sciences 34/3: 253-268.

Departamento de la Dona (1987): Recomendaciones para un uso no sexista de la Lengua. Recomandacions per a un ús no sexista de la llengua. Valencia: Departamento de la Dona. Consellería de Cultura, Educación y Ciencia de la Generalitat Valenciana.

Diputación de Córdoba (2005): Resolución del Presidente de la Diputación de Córdoba para propiciar el uso del lenguaje no sexista en los documentos de la institución y sus organismos. http://www.dipucordoba.es/uploads/attachments/155/resolucion-lenguaje-nosexista.pdf?F1250151849, accessed February 13, 2013.

Dumais, Hélène (1988): Pour un genre à part entière. Québec: Ministère de l'Éducation.

Dumais, Hélène (1992): "Rédaction non sexiste: repères bibliographiques". Recherches féministes 5/1: 175-177.

Errazu Colás, Ángeles, María (1995): Recomendaciones para un uso no sexista del lenguaje. Zaragoza: Instituto Aragonés de la Mujer.

Fleischman, Suzanne (1997): "The battle of feminism and Bon Usage: Instituting non sexist usage in French". The French Review 70/6: 834-844.

Frank, Francine Wattman/Treichler, Paula (1989): Language, Gender and Professional Writing. New York: Modern Language Association.

Gastil, John (1990): "Generic pronouns and sexist language: The oxymoronic character of masculine generics". Sex roles 23 (11/12): 629-643.

García Meseguer, Álvaro (1994): ¿Es sexista la lengua española? Una investigación sobre el género gramatical. Barcelona: Paidós.

Guentherodt, Ingrid et al. (1980): "Richtlinien zur Vermeidung sexistischen Sprachgebrauchs". Linguistische Berichte 69: 14-21. 
Gygax, Pascal et al. (2008): "Generically intended, but specifically interpreted: When beauticians, musicians, and mechanics are all men". Language \& Cognitive Processes 23/3: 464-485.

Gygax, Pascal/Gabriel, Ute (2008): "Can a group of musicians be composed of women? Generic interpretation of French masculine role names in the absence and presence of feminine forms". Swiss Journal of Psychology 67/3: 143-151.

Hamilton, Mykol Cecilia (1988): "Using masculine generics: Does generic 'he' increase male bias in the user's imagery". Sex roles 19 (11/12): 785-799.

Henley, Nancy M./Abueg, Joselito (2003): "A review and synthesis of research on comprehension of the masculine as a generic form in English". Estudios de Sociolingüística: Linguas, Sociedades e Culturas 4/2: 427-454.

Instituto de la Mujer, Gobierno de Canarias (2010): Guía sobre recursos existentes sobre lenguaje no sexista. http://portal.grancanaria.com/portal/RWcab/DOCUMENTOS/ 1/0_18382_1.pdf, accessed February 13, 2013.

Irmen, Lisa/Roßberg, Nadja (2004): "Gender markedness of language. The impact of grammatical and nonlinguistic information on the mental representation of person information". Journal of Language and Social Psychology 23/3: 272-307.

Irmen, Lisa/Linner, Ute (2005): "Die Repräsentation generisch maskuliner Personenbezeichnungen. Eine theoretische Integration bisheriger Befunde". Zeitschrift für Psychologie 213, 3: 167-175.

Klein, Josef (1988): "Benachteiligung der Frau im generischen Maskulinum - eine feministische Schimäre oder psycholinguistische Realität?" In: Oellers, Norbert (ed.) (1988): Das Selbstverständnis der Germanistik. Tübingen, Max Niemeyer: 310-319.

Koziar, Marissa (2009): Gender exclusive language: Effect on perception and moderating influence through awareness of effect. Dissertation. (Publication number: 3352854). Walden University: Minnesota.

Krugova, Marina S. (2007): "Linguistic Gender Policies in Contemporary Spain". Filologiya 61 (9/2): 103-111.

Luraghi, Silvia/Olita, Anna (eds.) (2006): Linguaggio e genere. Grammatica e usi. Rome: Carocci.

MacKay, Donald G. (1980): "Prescriptive grammar and the pronoun problem". In: Henley, Nancy et al. (eds.) (1980): Language and sex, II. Rowley/Mass., Newbury House: 38-53.

Marcato, Gianna/Thüne, Eva-Maria (2002): "Gender and Female Visibility in Italian". In: Hellinger, Marlis/Bußmann, Hadumod (eds.) (2002): Gender across Languages. The Linguistic Representation of Women and Men. Vol 2. Amsterdam/Philadelphia, John Benjamins: 187-217.

Martyna, Wendy (1978): Using and understanding the generic masculine: a socialpsychological approach to language and the sexes. Ph.D. dissertation. Ann Arbor (Michigan): University Microfilms.

Miller, Casey/Swift, Kate (1981): The handbook of non-sexist writing for writers, editors and speakers. London: The women's press.

Ministerio de Educación y Ciencia (1988): Recomendaciones para el uso no sexista de la lengua. Madrid: Ministerio de Educación y Ciencia.

Moreno Cabrera, Juan Carlos (2012): Acerca de la discriminación de la mujer y de los lingüistas en la sociedad. Reflexiones críticas. http://infoling.org/repositorio/ MORENOSEXISMO.pdf, accessed February 13, 2013.

Moulton, Janice et al. (1978): "Sex bias in language use: 'Neutral' pronouns that aren't". American Psychologist 33: 1032-1036.

Nagle, Traci C. (2008): "Women's Attitudes towards Sexist/Nonsexist Language across the Lifespan". IULC Working Papers 8: Abstract at https://www.indiana.edu/ iulcwp /abstracts.cgi?which=08\#08nagle23, accessed September 23, 2012. 
Ng, Sik Hung (1994): "Androcentric coding of man and his in memory by language users". Journal of Experimental Social Psychology 26: 455-464.

Nissen, Uwe Kjær (1997): "Do sex-neutral and sex-specific nouns exist: The way to nonsexist Spanish?" In: Linck, Gudula/Pasero, Ursula (eds.) (1997): Kommunikation von Geschlecht. Communication of gender. Pfaffenweiler, Centaurus: 222-241.

Nissen, Uwe Kjær (2002): "Gender in Spanish: Tradition and innovation". In: Hellinger, Marlis/Bußmann, Hadumod (eds.) (2002): Gender across languages: The linguistic representation of women and men. Vol. 2. Amsterdam/Philadelphia, John Benjamins: 251279.

Núñez Cedeño, Rafael A. (1999): "En torno a la neutralidad genérica del pronombre él". In: Ortiz López, Luis A. (ed.) (1999): El Caribe hispánico: Perspectivas lingüísticas actuales. Homenaje a Manuel Álvarez Nazario. Frankfurt/Madrid, Iberoamericana: 119-129.

Ramírez Vélez, Juan Manuel (2009): 10 recomendaciones para el uso no sexista del lenguaje. Mexico: Conapred.

Real Academia Española (1977): Esbozo de una nueva gramática de la lengua española. Madrid: Espasa-Calpe.

Real Academia Española (2012): Sexismo lingüístico y visibilidad de la mujer. http://www.rae.es/rae/gestores/gespub000040.nsf/(voanexos)/arch50C5BAE6B25C8BC8C 12579B600755DB9/\$FILE/Sexismo_linguistico_y_visibilidad_de_la_mujer.pdf, accessed February 13, 2013.

Rothermund, Klaus (1998): "Automatische geschlechtsspezifische Assoziationen beim Lesen von Texten mit geschlechtseindeutigen und generisch maskulinen Text-Subjekten". Sprache und Kognition 17: 152-166.

Rubin, Donald L./ Greene, Kathryn/Schneider, Deidra (1994): "Adopting Gender-Inclusive Language Reforms: Diachronic and Synchronic Variation". Journal of Language and Social Psychology 13/2: 91-114.

Stahlberg, Dagmar/Sczesny, Sabine/Braun, Friederike (2001): "Name your favorite musician: Effects of masculine generics and of their alternatives in German". Journal of Language and Social Psychology 20/4: 464-469.

T-incluye.org (2008): Recopilatorio de recursos web sobre lenguaje NO sexista. http://www.mujeresenred.net/IMG/pdf/recopilatorio_lenguajenosexista.pdf, accessed February 13, 2013.

UNESCO (1990): Recomendaciones para un uso no sexista del lenguaje. Paris: UNESCO. http://www.ucm.es/info/ucmp/cont/descargas/documento5681.pdf, accessed February 13, 2013. 